\title{
NEW MEDIA, NEW RESEARCH CHALLENGES AN INTRODUCTION SLAVKO SPLICHAL
}

\begin{abstract}
The authors introduce the European Science Foundation Forward Look Report Media in Europe: New Questions for Research and Policy (2013) which summarises the conclusions and recommendations of a series of ESF workshops held in 2012 to draw up a strategic research and science policy agenda for media studies in Europe for the next 5-10 years.

The presentations in five meetings, along with informal dialogue and exchanges, shed greater light on the pervasive role of the media in so many areas of social, economic, cultural and political life. Five articles based on the ESF workshop position papers by the same authors, debates in the workshops and the final conference held in Ljubljana in January 2013, and respective chapters of the ESF Forward Look Report, discuss current trends in mediated identity formation, the 'digital divide' conundrum, political participation

in an age of mediatisation, the agency of content creators, and research literature on media literacy.
\end{abstract} Peter Golding is ProViceChancellor (Research and Innovation), Northumbria University; e-mail: peter.golding@northumbria. ac.uk.

Slavko Splichal is Professor at the Faculty of Social Sciences, University of Ljubljana, and Fellow of the Slovenian Academy of Sciences and Arts; e-mail: slavko.splichal@fdv.uni-lj.si. 
The contributions to this issue of Javnost-The Public develop themes explored in the ESF Forward Look final report Media in Europe: New Questions for Research and Policy. The European Science Foundation instrument called the 'Forward Look' is designed to develop medium to long-term views and analyses of future research developments in specific research areas with the aim of defining a set of key research questions that should be addressed at national and European level. By assessing what is known and what needs to be known, the Forward Looks try to identify the ways in which research can advance knowledge and steer the development of policy and practice.

Of all different spheres of social life being transformed by digital technologies, mass mediated communication is undergoing the most significant changes, which can be characterised in terms of digitisation, globalisation and commodification. Given the pervasive role of the media in so many areas of social, economic, cultural and political life, the field of media studies will become even more important in the years to come. In this context, the ESF Forward Look "Media Studies: New Media and New Literacies" (2012-2013) has drawn up a strategic research and science policy agenda for media studies for the next 5-10 years. The Report outlines the research priorities in the field of media studies in Europe in the years ahead, focusing on four broad clusters of critical issues: (1) political engagement, (2) digital divides, (3) the creative economy, and (4) identity formation.

This Forward Look grew up from a workshop initiated by the ESF Standing Committees for the Humanities (SCH) and the Social Sciences (SCSS) in response to the need for a better coordinated development of research initiatives that stretch across the (methodological) divides between the humanities and social sciences. Following the example of the ESF Research Networking Programme "Changing Media, Changing Europe" (2000-2004) focused on the development of media as part of the modernisation and globalisation of society, the new initiative brought together researchers from different backgrounds in the humanities and social sciences, to outline the priorities for future research and to sketch funding initiatives crossing traditional borders between different disciplines in media studies.

The FL report Media in Europe: New Questions for Research and Policy summarises the conclusions and recommendations of a series of four ESF workshops held in 2012 in Helsinki, Nicosia and Lisbon, and the final conference in Ljubljana in January 2013. The meetings brought together in an interdisciplinary dialogue scholars and researchers representing different areas of social sciences and humanities from almost all European countries. The presentations in five meetings, along with informal dialogue and exchanges, shed greater light on the pervasive role of the media in so many areas of social, economic, cultural and political life. In this special issue of Javnost-The Public on new questions on media research and policy in Europe, we share with you five articles based on the ESF workshop position papers by the same authors, debates in the workshops and the final conference, and respective chapters of the ESF Forward Look report Media in Europe: New Questions for Research and Policy published at the same time as this theme issue.

Recent years have witnessed an unprecedented growth in research - in terms of publications, scholars and students - in the field of communication and media studies in Europe and elsewhere. "Over the past 50 years, the associated fields of communication and media studies have expanded perhaps more than any other academic field apart from computer science and biomedicine" (Nordentstreng 
2012 , 1). It is true that the field is flush with resources that some other disciplines may only dream of, including an increase in the number of students at all levels of higher education. Yet the same conditions that make media and communication departments at universities crammed by students also maintain their relatively low status in the research community. However, while communication as a research field is believed to have made one of the greatest growths of all academic fields over the last 50 years, it is also believed that it has become increasingly heterogeneous and diversified, mirroring its intellectual origins and goals, powerful changes in the media landscape as well as its socio-cultural significance (Splichal \& Dahlgren 2013). Because of the conceptual and paradigmatic divisions, the field still lacks identity and tends to lose normative orientation in empirical research (Donsbach 2005).

With the advent of the internet, research on ('new') media was adopted by almost all disciplines in the social sciences as well as humanities. The ubiquity of the Internet in social relations makes it more than just new information and communication technology; its development embodies, reproduces, and sustains forms of social organisation spread through the entire social structure. With one of the seven 'flagship initiatives' of the 'Europe 2020 Strategy', the European Commission committed itself to

maximise the social and economic potential of ICT, most notably the internet, a vital medium of economic and societal activity: for doing business, working, playing, communicating and expressing ourselves freely. Successful delivery of this Agenda will spur innovation, economic growth and improvements in daily life for both citizens and businesses. ... [Digital technologies] will provide Europeans with a better quality of life through, for example, better health care, safer and more efficient transport solutions, cleaner environment, new media opportunities and easier access to public services and cultural content (Digital Agenda 2010, 3).

There is increasing optimism that new communication technologies will bring significant advances in human life. The internet can indeed empower individuals and groups to 'construct' new communities and spaces of shared interests but their agency can only be efficacious within properly regulated political and economic conditions on both national and transnational levels. Otherwise, the internet may generate new forms of marginalisation and exclusion. For example, with the new interactive virtual spaces it has created, the internet increased the possibility of citizens' participation in political discourse beyond national boundaries but the mere extension of communication networks does not yet provide (new) opportunities for citizens' participation in political processes.

Both the general optimism invested in the increasing use and availability of digital media and the new research challenges have stimulated governmental and non-governmental actors, science and funding organisations to undertake systematic reviews of the current status and trends in the field in order to identify potential opportunities for better and perhaps more legitimate social use of new communication technologies and media, and to determine priorities for future funding. The articles collected in this issue of Javnost-The Public present a number of prospective directions in media research, illustrating their potential relevance and/or societal impact. They summarise the key defining features of the issues demanding research priority in the field of media studies in Europe in the years 
ahead. Authors of the articles in this issue make it clear that research on media is closely related to questions of economic and technological developments, public policy and the state, and more broadly to social, economic and cultural issues. They do not suggest that their observations exhaust the research priorities or possibilities in this field; nevertheless, the ideas expressed in the following pages do represent a range of vital and pressing questions to be addressed in the near future.

The first article "Mediated Identity Formation: Current Trends in Research and Society" by Johan Fornäs and Charis Xinaris discusses the changing conditions of identity formation in a media-saturated society. The authors identify a wide range of connections and interdependences between media, users, and broader cultural developments while discussing the relationship between the formation of personal and collective identities and media developments in contemporary societies, recognising the many ways in which the media are both a resource for the construction of identity and a means for its dissemination and publication. They see media competence (which includes not only access to the media but also the ability to critically assess and process media content) as directly relevant to the processes of identity formation.

Although a variety of approaches to identity formation from a media studies perspective exist, the authors suggest that relevant research questions and topics of investigation in this area may be summarised under three fundamental thematic categories. (1) The first category of questions is concerned with defining and describing ongoing changes of identity formation. Since issues of media competence and identity formation always implicate issues of power, more research is needed to find out how interactive mechanisms between media practices, identity formations and democratic politics actually function. (2) Equally urgent is research that uncovers the media-related causes behind current identity transformations, including matters of technology, form and context of communication, as well as the roles of the digital media. (3) Finally, research is needed to recognise and explain the consequences of new modes of identity formation as they affect the development of transcultural identities and the issue of empowerment.

In the article on "What Is the 'Digital Divide' and Why Is It Important?", Colin Sparks presents a clear and balanced overview of research concerning digital divides, thus integrating diverse positions and sources of research, including institutions such as the OECD. The article concentrates on one aspect of access in advanced economies - on familial and individual access and usage of digital media. While the author admits that access to, and use of, new information and communication technologies in the workplace is clearly central to understanding the experience of labour in the 21st century, he had to restrict his contribution to access in the home and individual usage of ICTs which to some degree (still) overlaps with the consumption of the 'old' (print, broadcasting, cinema, recorded music etc.) media.

As the author argues, it is unlikely that in the future network society every last aspect of social life will depend upon using information and communication technologies, but the range of significant activities which will do so will almost certainly increase. At the same time, the digital divide may well be deepening, as it is not only reflecting existing social structures and pre-existing inequalities but also helping to form and reproduce them. Large political and social questions of equity and efficiency do not disguise that, however complex and multi-dimensional, inequities in access to and ability to use new communication technologies persist, 
and endure beyond what once was expected to be ephemeral. Thus it is important to identify sources and forms of social disadvantage and inequality in the use and ownership of communication facilities both nationally and internationally. The author concludes that questions about who has what kinds of access, knowledge, experience, confidence and opportunity to sustain an acceptable standard of life in the future network society will become increasingly central to all social inquiry as well as to the distribution of power and resources within society itself.

The article on "Political Participation in an Age of Mediatisation" written by Peter Dahlgren and Claudia Alvares, outlines the importance of mediatisation, the saturation of political communication of all kinds by media, and suggests the need for a renewed research focus on the nature of alternative democratic politics. The article suggests prioritising research that considers "political agency in context" and sets out a number of themes that would follow from such a perspective.

The authors present a coherent overview of research regarding the relationship between two key areas of concern in the modern world: democratic political participation and the contemporary media environment. They question the presumption that technology will inevitably and insistently enlarge possibilities for political action and mobilisation, not least because of its potential for by-passing representative organisations and institutions, and the possibility that selective exposure in a diverse and individualised communication environment could emphasise the reinforcement of attitudes as much as constructive dialogue. One of the strengths of this contribution is the elaboration of the ways in which formal as well as informal practices of political engagement relate to media and their everyday uses by citizens. Whereas 'publicness' of the public sphere has traditionally been conceptualised in terms of rational deliberation, it is now increasingly linked to digital multimedia channels that often privilege other and different forms of political expression, including the visual, the symbolic, the affective, and the experiential. The textual has not disappeared, but text online tends to be more cursory than in print, and shares the stage with other communicative modes. As the authors believe, this shift may also correspond to an increasingly visible dichotomy between traditional institutional and non-institutional, alternative politics.

They suggest that research on media and democracy, especially concerning engagement and participation, needs to be rethought not only in the light of the rapidly changing media landscape but also in relation to the current crises of economies, welfare, political participation, and private-public provision. These crises are altering the life circumstances of many citizens as well as threatening the character and quality of democracy itself. The very notion and practice of citizenship in a democracy, in other words, is at issue, with the media in all their forms and changing nature at the heart of engagement and empowerment.

Ola Erstadt's article, "The Agency of Content Creators - Implications for Personal Engagement and Media Industries," focuses on the interconnection between different levels that creative cultural production represents, from the social practices of individuals to collective orientations in media use and macro processes of the creative economy in Europe. It is argued that, "A focus on content creation among audiences implies a reorientation towards the productive mode, and how this has moved from the domain of professionals in media organisations towards a common practice among people in their everyday lives."

While much research has looked into everyday experience and the values, ideas, 
beliefs, and attitudes of consumers, there is much less known about the acts and structures behind both creation and creativity. There remains a need to depart from the residue of romantic excess imbued in the concept of creativity, and to understand better the relationship of symbolic to material value in the content of communications. One resource for taking this research forward is in the rediscovery and deployment of various ethnographic methodologies, and to recognise that media research has always, for reasons of access and practicality, been unable to generate the volume of 'production studies' required to obtain a balanced understanding of the full communications process. There remains much to understand about the qualities, activities, and character of the creative workforce and creative industries in three key areas: media creativity, social practices of audiences, and the impact of technological developments on the creative and cultural economy.

In the initial Forward Look Proposal "Media Studies: New Media and New Literacies" submitted to the ESF Directorate in spring 2008, the issue of media literacy was the guiding concept and focus. The concept was much debated, and these debates are reflected in the review essay "From Protection to Public Participation" provided by Ola Erstad and Synnøve Amdam. As debate evolved in the development of the Forward Look, it became increasingly necessary to go beyond many of the issues raised in discussing media literacy in order to formulate proposals for research and policy responding to the pervasive role of the media in so many areas of social, economic, cultural and political life. Yet Erstad's and Amdam's essay presents a solid, constructive, and useful review of previous research on media literacy. One of its strengths is the specification of literacy simultaneously as an individual capacity and a social practice.

The articles presented in this issue of Javnost-The Public reflect the combined ideas offered by numerous specialists from different countries having participated in the four ESF workshops, whose contribution is briefly described and acknowledged in each of the articles included in this issue.

We wish to express our profound thanks to Professor Klaus Bruhn Jensen and Professor Ed Mcluskie who thoroughly reviewed the contributions to this issue. Their cogent, lucid and constructive comments and suggestions were an invaluable assistance to the authors.

Words of thanks should also be addressed to the European Science Foundation for its kind financial support and to the ESF team from Strasbourg, particularly to Dr. Eva Hoogland and Sarah Moore.

\section{References:}

Digital Agenda for Europe. 2010. Communication from the Commission to the European Parliament, the Council, the European Economic and Social Committee and the Committee of the Regions. /* COM/2010/0245 final * < http://eur-lex.europa.eu/LexUriServ/LexUriServ. do? uri=CELEX:52010DC0245:EN:NOT>

Donsbach, Wolfgang. 2006. Presidential Address: The Identity of Communication Research. Journal of Communication 56, 3, 437-448.

Golding, Peter, Slavko Splichal et al., eds. 2013, forthcoming. Media in Europe: New Questions for Research and Policy. Strasbourg: ESF.

Nordenstreng, Kaarle. 2012. Communication Research Has Expanded Phenomenally since the 1950s, but Where Has It Taken Us? Paper at EURICOM Colloquium, Piran (Slovenia), 16-17 November 2012.

Splichal, Slavko, Peter Dahlgren. 2013, forthcoming. Media Research Paradigms: Conceptual Distinctions, Continuing Divisions. In F. Darling-Wolf (ed.), Blackwell's International Companion to Media Studies: Methods in Media Studies. Oxford, UK: Blackwell. 